\title{
ENHANCE LEARNING EXPERIENCE USING TECHNOLOGY IN CLASS
}

\author{
Luai Al-Labadi (iD, Saurabh Sant $(\mathbb{D}$ \\ Department of Mathematical and Computational Sciences, University of Toronto Mississauga (Canada) \\ luai.allabadi@utoronto.ca,saurabh.sant@mail.utoronto.ca
}

Received July 2020

Accepted September 2020

\section{Abstract}

Majority of the students now have access to portable devices that can provide countless information at their fingertips through various resources such as learning games and interactive applications. These resources allow immediate communication and interaction between students and instructors. In this study we measured students' perception of the effectiveness of using technological tools in lectures on their academic performance and their level of understanding of the course topic. Students, who have taken statistics courses at the University of Toronto completed a survey that identified variables connected to their perception of using technology in class and the ways in which, in turn, their learning experiences were enhanced. The results of the survey showed that a significant portion of students perceived that they gained a deeper level of understanding of lecture contents when technology was used in class. Thus, based on the results of our study, we recommend that instructors take advantage of using technology in their class in order to create a more immersive learning environment for their students than using traditional instructional methods.

Keywords - Mathematics, Mobile learning, Engagement, Perception, Performance, Statistics, Undergraduate.

\section{To cite this article:}

Al-Labadi, L. \& Sant, S. (2021). Enhance learning experience using technology in class. Journal of Technology and Science Education, 11(1), 44-52. https://doi.org/10.3926/jotse.1050

\section{Introduction}

As technology becomes widely accessible to students' overtime, there has been a trend among instructors utilizing technology in class to better engage students with course contents, compared to traditional teaching methods. Principles and Standards for School Mathematics state that: "Technology is essential in teaching and learning mathematics; it influences the mathematics that is taught and enhances students' learning" (NCTM, 2000: page 11). While educators have been trying to figure out ways to best incorporate a technological tool in class, there have been some limitations in their research on effectively adapt, for instance, mobile devices into teaching and learning (Wang \& Higgins, 2006).

Mobile learning (M-learning) or use of technology in class refers to using educational applications on laptops, phones, personal computers and tablets (Traxler, 2005). These technological applications facilitate the interaction between instructors and students in real time, since students can instantly answer and ask questions while using them. Moreover, instructors can clear students' misconceptions before moving onto 
the next topic or can focus on topics students find difficult. They can also create short quizzes or learning games to test for students' understanding of a topic. Thus, by including technological applications into live lectures, instructors will have the opportunity to optimize students' learning experience. Some notable educational applications include the use of Top Hat, iClicker, Piazza and Kahoot (Wang \& Tahir, 2020).

Furió, Juan, Seguit and Vivó (2015) compared mobile learning with traditional instructional methods. Although, students' learning outcomes in the two teaching methods were not statistically significant, the authors noted that, mobile learning was found to be more satisfying and immersive among students, and had a higher motivational effect compared to traditional learning methods that were used in classrooms.

The advantages of Mobile learning are that it provides instructors with immediate feedback from students, creates incentives for students to learn through scoring points, motivates collaboration with peers and fosters learning by trial and error.

Kim's (2019) study analyzed students' academic performance in a medical English course taught using traditional methods and mobile learning. Kim's study found mobile learning to be beneficial since students were able to provide instant text responses to their instructor's inquiry. As a result, instructors were provided with richer information about students' motivation and expectations of their learning. Instructors were also able to gauge students' level of understanding through quizzing tools and immediate feedback. Students performed significantly better by using the mobile learning as it provided them with active classroom engagement and frequent feedback. In turn, students enhanced their learning outcomes. The limitations of Kim's paper were that small sample size was used, and it did not provide direct evidence as to whether or not students' improvement of their learning was attributed to mobile learning. Other factors may have affected the learning outcomes in Kim's study, including students' past experiences, their social persuasions and their physiological and psychological states of mind.

Robb and Shellenbarger (2012) encourage the use of mobile learning in class. They remind educators that students are growing up in a technology-rich environment, and that, students thrive in their performance when immediate feedback are instantly provided to them from their instructors. They further note that, students tend to learn better by actively doing and discovering solutions to problems at hand. For instance, M-learning engages students to actively participate in class, maintain students' interest and can foster deeper understanding of the context being discussed in lectures.

As part of our study, we try to overcome some of the limitations highlighted in earlier studies by using a bigger sample size and define more variables that can contribute to students' perception of their learning experience when technology is used in class. We then try to determine the overall perception of students on the effectiveness of using technology in class by closely examining each variable included in this study.

The reminder of this paper is as follow. Section 2 discusses our motivation and objectives for this work. Section 3 describes our approach for implementing mobile learning in class. Section 4 involves constructing the questionnaire and the sampling process. Section 5 addresses descriptive analyses of the results. Section 6 describes our research methodology, in which we utilize a quantitative method for analyzing a survey data and identifying the significance of various variables (survey-items) for measuring students' perception of using technology in class to enhance their learning. The results of this paper are summarized in Section 7. We conclude the paper in Section 8. A copy of the Questionnaire is placed in the Appendix.

\section{Motivation and Objective}

Due to the advancement in technology, there has been an increase in preferences by students to use technology in class to help gain better understanding of the lecture material. However, quantitative studies that consider, for instance, the effect of using mobile learning on students' attitude toward mathematics are limited (Fabian, Topping \& Barron, 2016; Sung, Chang \& Liu, 2016; Wang \& Tahir, 2020). To address this gap in the educational literature, this study designed a survey to identify variables (survey-items) that 
will determine how students' perception of the use of technology in lectures are effective in undergraduate courses related to mathematics and statistics. Relying on the analysis of the survey data, we aim to propose short-term solutions that instructors can take advantage of when they use technology in class in order to enhance their students' learning experience.

\section{Background: Implementing Mobile Learning in Class}

To research the effect of mobile learning on students' perceptions of their learning experience in class, Top Hat (cf. www.tophat.com) was commonly used as the main educational application in Statistics courses at University of Toronto. Top Hat is an, in class, online learning tool. The instructor asks questions on the lecture slides and students' respond using their phones, iPads, laptops, or any other devices with an internet connection. Moreover, students are able to see their marks for the question being asked in the lecture, immediately after answering. The instructor may choose to provide students with part marks for participation and allocate the rest of the marks for when students provide correct answers. A small registration fee is required to be paid by students to use Top Hat in class. Special arrangements were made if the students did not have a device for answering lecture questions, or if the Top Hat fee is beyond their financial means.

Most students involved in this research studied at least one course using Top Hat in the Fall term and at least another course without using Top Hat (or any mobile learning tool) in the Winter term by the first author of this paper. Typically, in courses where Top Hat is incorporated, one or two Top Hat questions are considered in each lecture. Each question is marked out of 1 , with 0.5 marks for simply entering any answer and 0.5 marks for entering the correct answer. That is, about half of the marks are basically achieved through participation in lectures. Students must attend and answer questions in their registered lecture section to earn marks. Students receive an email from the instructor explaining in detail how to set up and use Top Hat in class. Once a student is registered, the answers to Top Hat questions are only recorded if the student is physically present in the lecture since Top Hat requires students share their live location. Students are allowed to miss responding up to 3 questions; if $n$ questions are asked, then the students' marks will be calculated out of $\mathrm{n}-3$. No other adjustments were made for missed quizzes to avoid unfair advantage among students. The total marks of Top Hat questions worth $10 \%$ of the total marks of in the course.

\section{Data Gathering Tool}

We designed an anonymous survey with 11 questions where each question refers to a variable (a survey-item) that attributes to learning experience in class. The questions were made to be short and concise as possible to avoid any ambiguity. Next, the instructor emailed and posted the anonymous survey on Statistics course websites via Quercus for students to complete. This urged them to fill out the questionnaire.

The questionnaire consisted of the following items (variables to be include in the analysis): (1) whether students' used technology in class before; (2) the extent to which using technology in class helped increase students' final mark; (3) the extent to which using technology in class increased engagement in class; (4) the extent to which using technology in class was beneficial in terms of understanding the course material; (5) the extent to which students recommend taking courses that uses technology; (6) the extent to which the subscription cost affected students' decision in using technology; (7) students' indication of the number of completed courses that used technology in them; (8) the extent to which the instructor answered students' concerns anonymously with the use technology; (9) the extent to which students agree whether more instructors should use technology in class; (10) the extent to which students prefer courses with the use of technology over courses without them; and (11) the extent to which students prefer to write quizzes using technology. The completion of survey was optional for students. The sample size for this study consists of students who genuinely wanted their opinions heard. A copy of the questionnaire can be found in the appendix. 


\section{Data Summary}

A total of 196 students studying statistics completed the survey near the end of winter semester in 2019-2020 academic year. Students who completed the survey were enrolled in upper-year statistics courses hence they had taken at least few courses which used technology in lectures.

Before analyzing the survey results, we had to ensure that the questions in the survey measures the research topic consistently and reliably, and are inter-related to each other. To determine the reliability and consistency of the test items in the survey, Cronbach's alpha was run on the entire sample size of 196 students. Internal consistency reliability was assessed using Cronbach's alpha to measure the internal consistency of the scale, with preferred values between 0.7 and 1 . The obtained Cronbach's alpha value of the study-questionnaire is 0.824 , which indicates that the survey-items are internally consistent and hence the questionnaire is reliable.

Table below summarizes the frequencies and percentage of responses to each of the survey-items in the questionnaire.

Based on 196 responses, $97 \%$ of the students have used mobile learning in classrooms. Majority $(67 \%)$ of the students agreed that they found use of technology in classroom to be beneficial in terms of their understanding of the material and would prefer courses with mobile learning methods over traditional methods (58\%). $50 \%$ of the students were able to have their questions/concern answered anonymously through the use of mobile learning and would prefer instructors to use mobile learning to enhance their understanding of a course topic.

\begin{tabular}{|c|c|c|c|}
\hline \multicolumn{2}{|r|}{ Item } & Frequency & Percentage \\
\hline \multirow[t]{3}{*}{1} & \multicolumn{3}{|c|}{ Used technology in Class } \\
\hline & Yes & 190 & 96.94 \\
\hline & No & 6 & 3.06 \\
\hline \multirow[t]{4}{*}{2} & \multicolumn{3}{|c|}{ Did using technology in class help increase your final mark? } \\
\hline & Yes & 104 & 54.7 \\
\hline & No & 20 & 10.6 \\
\hline & Neutral & 66 & 34.7 \\
\hline \multirow[t]{4}{*}{3} & \multicolumn{3}{|c|}{ Increase in engagement in class } \\
\hline & Yes & 106 & 55.8 \\
\hline & No & 31 & 16.3 \\
\hline & Neutral & 53 & 27.9 \\
\hline \multirow[t]{4}{*}{4} & \multicolumn{3}{|c|}{ Beneficial in terms of understanding the course material } \\
\hline & Yes & 131 & 68.9 \\
\hline & No & 19 & 10 \\
\hline & Neutral & 40 & 21.1 \\
\hline \multirow[t]{4}{*}{5} & \multicolumn{3}{|c|}{ Recommend taking courses which uses technology } \\
\hline & Yes & 114 & 60 \\
\hline & No & 21 & 11 \\
\hline & Neutral & 55 & 29 \\
\hline \multirow[t]{4}{*}{6} & \multicolumn{3}{|c|}{ Subscription cost affect your decision } \\
\hline & Yes & 74 & 38.9 \\
\hline & No & 53 & 27.9 \\
\hline & Neutral & 63 & 33.2 \\
\hline \multirow[t]{2}{*}{7} & \multicolumn{3}{|c|}{ Number of courses taken that used technology } \\
\hline & Used for 1 course & 15 & 7.9 \\
\hline
\end{tabular}




\begin{tabular}{|r|l|r|r|}
\hline \multicolumn{1}{|c|}{ Item } & Frequency & \multicolumn{2}{|c|}{ Percentage } \\
\hline & Used for 2 courses & 44 & 23.2 \\
\hline & Used for 3+ courses & 130 & 68.9 \\
\hline 8 & Did the instructor answer your concerns anonymously due to technology? \\
\hline & Yes & 96 & 50.5 \\
\hline & No & 35 & 18.4 \\
\hline & Neutral & 59 & 31.1 \\
\hline 9 & Should more instructors use technology in class? \\
\hline & Yes & 126 & 67 \\
\hline & No & 44 & 23.4 \\
\hline & Neutral & 18 & 9.6 \\
\hline 10 & Prefer courses with technology over courses without & 36.3 \\
\hline & Yes & 69 & 20 \\
\hline & No & 38 & 43.7 \\
\hline & Neutral & 83 & 37.9 \\
\hline 11 & Prefer to write quizzes using technology & 34.2 \\
\hline & Yes & 72 & 27.9 \\
\hline & No & 65 & 53 \\
\hline & Neutral & & \\
\hline
\end{tabular}

Table 1. Frequency analysis for each item in the survey

\section{Research Methodology}

We used quantitative methodology to understand students' perception of the effect of using technology in statistics courses on their learning experience. The quantitative methodology reflects the philosophical underpinning of positivism, which asserts that knowledge (e.g., perception of learning) can be examined through observation and numeric data collection from a large number of people, which can help explain why individuals (e.g., statistics students) behave the way they do (Sears \& Cairs, 2010). For instance, a survey design can provide quantitative descriptions regarding a large number of individuals' perceptions (Creswell, 2012).

To test the significance of each item from the questionnaire, we employed one-sided $\mathrm{z}$ test for proportion with significance level of 5\%. We combined positive responses "Agree" or "Strongly Agree" to each survey-item and denoted them as a "Yes" response. We combined negative responses "Disagree" or "Strongly Disagree" to each survey-items and denoted them as a "No" response. For the purpose of our study, we did not include into our analysis "Neutral" responses since we could not determine in which direction such response to an item tends to lean towards. Hence, the sample size of the significance test for each variable (survey-item) is the number of students who responded either "Yes" or "No" to a question. In the one-sided $\mathrm{z}$ test we define yes-responses correspond to frequency of "success" and no-responses correspond to frequency of "not success" among the total frequency (that is, the total number of students responding as either Yes or No) in each survey-item. The hypothesis test below was conducted for each item. We let $\mathrm{p}$ be the true proportion of students who believe using technology in class helped them in terms of each item presented in Table 2. Thus, the ratio, p, was calculated using two categories of responses: Yes, No. We consider the following hypotheses:

$$
\mathrm{H}_{0}: p=0.5 \quad \text { VS } \quad \mathrm{H}_{1}: p>0.5
$$

The above statement means that we are testing, for example, whether the true proportion of students who perceive that using technology in class helped them in terms of each of items asked in the survey exceeds 0.5 . 
As expected, one of the many advantages of using technology in class was that majority of the students indicated that they gained a greater level of understanding of the course material. This is evident from the significant test of item 3 in Table 2 in which the p-value is notably less than 0.05 (significance level).

Table 2 summarizes the significance of each item's test along with their corresponding p-values reported.

\begin{tabular}{|l|c|c|}
\hline \multicolumn{1}{|c|}{ Item } & P-value & \multicolumn{1}{c|}{ Test } \\
\hline Did using technology in class help increase your final mark? & $<0.0000001$ & Significant \\
\hline Increase in engagement in class & $<0.0000001$ & Significant \\
\hline Beneficial in terms of understanding the course material & $<0.000001$ & Significant \\
\hline Recommend taking courses which uses technology & $<0.000001$ & Significant \\
\hline Subscription cost affect your decision & 0.03797 & Significant \\
\hline Did the instructor answer your concerns anonymously due to technology? & 0.000000008 & Significant \\
\hline Should more instructors use technology in class? & $<0.0000002$ & Significant \\
\hline Prefer courses with technology over courses without & 0.001865 & Significant \\
\hline Prefer to write quizzes using technology & 0.3041 & Insignificant \\
\hline
\end{tabular}

Table 2. $\mathrm{p}$-values of one-sided $\mathrm{z}$ tests

\section{Results}

Z-tests were conducted to investigate which variables (survey-items) aided in the improvement of students' perception of their learning experience. Based on the results, there is strong evidence to conclude that proportion of students who perceived that the use of technology in class helped improve students' overall learning experience in undergraduate courses related to mathematics and statistics were significantly above 0.5 . This means that, majority of the students benefited as they believed that their final grade in the course increased. Furthermore, more students indicated that they were engaged in lectures and were able to have their questions or concerns answered by instructors in real time. This resulted in a noteworthy higher proportion of students who indicated that they understand the lecture material. Moreover, bulk of the students preferred taking courses that uses technology over courses that do not and would recommend more instructors to start utilizing mobile learning to improve the learning experience of their students. However, there were mixed responses in terms of proportions of students who prefer to write quizzes using technology or not.

\section{Limitations and Conclusion}

This was an observational study that invited students who took Statistics courses at the University of Toronto to report their learning experiences with course contents in which their instructor used technology to facilitate their learning. It is yet to be determined if similar results follow for courses in other fields of study and other universities. Furthermore, this study utilized a survey to measure students' perception of the use of technology on their learning experience. Therefore, causal relationships or inferences cannot be established. We recommend that future studies design experiments to investigate the effects of using technology in instructional methods on students' learning outcomes. Such studies would compare students' academic performance in the experimental group where technology is being used in class with the control group where technology is not being used in class. Moreover, future studies should consider measuring students' perception of their learning experience and how students' perception of their learning is affected by the teaching condition that they are situated in.

In light of many advancement in technology, instructors can support and enhance their students' academic performance by incorporating a technological tool into their instructional design. If technology is implemented properly and used strategically, it can completely outweigh the benefits of using traditional teaching methods. Students will be able to solidify their understanding of even the most mundane topics taught in some courses. An ideal classroom setting would be where communication between students and instructors is maximized. In turn, instructors are better able to foster deeper learning and, in turn, change 
their students' perceptions to more positive views regarding the subject being taught. Student-instructor communication can be supported by taking advantage of technological tools in both teaching and learning.

\section{Declaration of Conflicting Interests}

The authors declared no potential conflicts of interest with respect to the research, authorship, and/or publication of this article.

\section{Funding}

The authors received no financial support for the research, authorship, and/or publication of this article.

\section{References}

Creswell, J.W. (2012). Educational Research: Planning, Conducting, and Evaluating Quantitative and Qualitative Research. Boston, MA: Pearson Education, Inc.

Fabian, M., Topping, K., \& Barron, I. (2016). Mobile technology and mathematics: effects on students' attitudes, engagement, and achievement. Journal of Computer in Education, 3(1), 77-104. https://link.springer.com/article/10.1007/s40692-015-0048-8

Furió, D., Juan, M.C., Seguit, I., \& Vivó, R. (2015). Mobile vs. traditional learning. Journal of Computer Assisted Learning, 31, 189-201. https://doi.org/10.1111/jcal.12071

Kim, K.J. (2019). Enhancing students' active learning and self-efficacy using mobile technology in medical English classes. Korean Journal of Medical Education, 31(1), 51-60. https://doi.org/10.3946/kjme.2019.118

NCTM (2000). Principles and Standards for School Mathematics. Reston, VA: NCTM.

Robb M. \& Shellenbarger, T (2012). Using Technology to Promote Mobile Learning. Nurse Education, 37(6), 258-261. https://doi.org/10.1097/NNE.0b013e31826ł27da

Sears, A., \& Cairns, J. (2010). A Good Book in Theory: Making Sense Through Inquiry (2nd ed.). Toronto: University of Toronto Press.

Sung, Y.T., Chang, K.E. \& Liu, T.C. (2016). The effects of integrating mobile devices with teaching and learning on students' learning performance: A meta-analysis and research synthesis. Computer \& Education, 94, 252-275. https://doi.org/10.1016/j.compedu.2015.11.002

Traxler, J. (2005). Defining mobile learning. In Proceedings of the LADIS International Conference: Mobile Learning 2005 (261-266). Qawra, Malta.

Wang, A.I., \& Tahir, R. (2020). The effect of using Kahoot! for learning - A literature review. Computer \& Education, 149, 103818. https://doi.org/10.1016/j.compedu.2020.103818

Wang, S., \& Higgins, M. (2006). Limitations of mobile phone learning. The JALT CALL Journal, 2(1), 3-14. https://doi.org/10.29140/jaltcall.v2n1.18 


\section{Appendix}

\section{Use of technology in class}

The purpose of this survey is to analyze the impact of using technology (such as: iClicker, Top Hat, Kahoot or any interactive platform to communicate with the Instructor) within a course on student's overall academic performance. All information will be confidential. Thank you for your time and cooperation.

1. Have you used technology in a course?

o $\quad$ Yes

2. Did using technology in class help you to increase your final mark?

o Strongly Disagree

o Disagree

o Neutral

o Agree

o Strongly Agree

3. Were you more engaged in a lecture with technology compared to lectures that do not use technology?

o Strongly Disagree

o Disagree

o Neutral

o Agree

o Strongly Agree

4. Would you say that the use of technology in class is beneficial in terms of understanding the lecture topic?
o Strongly Disagree
o Disagree
o Neutral
o Agree
o Strongly Agree

5. Do you agree with the statement: "I would recommend someone to take a class that uses technology"?
o Strongly Disagree
o Disagree
o Neutral
o Agree
o Strongly Agree

6. Did the cost of subscription affect your decision in using technology in class?

o Strongly Disagree (I bought subscription regardless of price)

o Disagree

o Neutral

o Agree

o Strongly Agree (I did not buy subscription regardless of price)

7. How often did you use technology in your courses in your school career?

o I used it for 1 course

o I used it for 2 courses

o I used it for more than 3 courses 
8. Do you agree with the statement: "My professor was able to have my questions/concerns answered anonymously because of the use of technology in class"?

$\begin{array}{ll}\text { o } & \text { Strongly Disagree } \\ \text { o } & \text { Disagree } \\ \text { o } & \text { Neutral } \\ \text { o } & \text { Agree } \\ \text { o } & \text { Strongly Agree }\end{array}$

9. Do you want more professors to start using technology in class so that students can ask questions anonymously?
o Strongly Disagree
o Disagree
o Neutral
o Agree
o Strongly Agree

10. Do you agree with the statement: "I prefer a course that uses technology in class over a course that does not"?
o Strongly disagree
o Disagree
o Neutral
o Agree
o Strongly agree

11. Do you agree with the statement: "I prefer to write quizzes through Top Hat or iClicker over writing quizzes on paper"?
o Strongly Disagree
o Disagree
o Neutral
o Agree
o Strongly Agree

Published by OmniaScience (www.omniascience.com)

Journal of Technology and Science Education, 2021 (www.jotse.org)

\section{(c) (i) (8)}

Article's contents are provided on an Attribution-Non Commercial 4.0 Creative commons International License. Readers are allowed to copy, distribute and communicate article's contents, provided the author's and JOTSE journal's names are included. It must not be used for commercial purposes. To see the complete licence contents, please visit https://creativecommons.org/licenses/by-nc/4.0/. 